\title{
Correlation of social mechanisms of corruption and social climate
}

\author{
Vadim Burukin ${ }^{1}$, Viktor Vezlomtsev ${ }^{1, *}$, Svetlana Vezlomtseva ${ }^{1}$, and Olesya Zarubina ${ }^{1}$ \\ ${ }^{1}$ Academy of the Federal penitentiary service of Russian Federation, 1, Sennaya str., 390000, Ryazan, \\ Russia
}

\begin{abstract}
This study shows that corruption in the modern world is viewed as a negative form of deviant behavior in the sphere of state and municipal administration, as a destructive factor in public life, which largely determines the social climate in society and the state of national security. Corruption is an obstacle to the development of real democracy and to the growth of the well-being of the population. It has multiple reasons and grounds for spreading on the political, economic, cultural, socio-structural levels. All its manifestations are more tangible in real social life, affect the level and degree of protection of citizens, the ensuring of their rights and freedoms. This article identifies and analyzes the main socio-cultural determinants of the institutionalization of corruption in modern society.
\end{abstract}

\section{Introduction}

The topic of corruption is one of the most attractive for researchers of the widest range over the past decades. The fact is that this is an extremely paradoxical phenomenon, since the theoretical degree of its knowledge, as well as the intensity of practical measures to combat it, do not contribute to either eradicating or even reducing its manifestations. Corruption is systemic in nature and affects almost all spheres of society: social, economic, political, etc. In addition, corruption directly threatens people's lives. This can manifest itself in different forms: floods, the construction industry, the environment. A separate study can be written about each of these forms, but now we will focus on the environmental problem, since this is a long-term problem facing humanity. Unfortunately, corruption in general exacerbates existing problems in this area. According to the United Nations information on drugs and crime, environmental corruption includes: embezzlement in the implementation of environmental programs, widespread corruption in the issuance of permits and licenses for the exploitation of natural resources, and petty bribery of law enforcement officials. The UN has also identified the sectors most at risk: these include forestry, oil production, trade in endangered species and disposal of hazardous waste. Many of the world's largest timber producers and exporters, including Brazil, Indonesia, and others, have experienced significant environmental damage from illegal logging, which was made possible by corrupt officials. More than half of the world's timber in recent years is the result of such logging, with most of it related to bribery and corruption.

\footnotetext{
*Corresponding author: a.copytowa@yandex.ru
} 
In 2011, in terms of endangered species, the head of the anti-trafficking (against wildlife trafficking) non-governmental organization «Freeland» stated against South-East Asia that the number one problem faced by his organization as part of its anti-trafficking program (related to human trafficking) is corruption, especially corruption at a high level. Corruption can contribute to the extinction of various species of wildlife [1, p. 12].

As we can see, corruption continues to have an extremely negative impact on the life of society as a whole, on its everyday reality, so scientists are trying to expand the boundaries of existing approaches to this serious violation.

Nowadays, corruption is most often viewed either in an economic or in a political context. In our opinion, it is impossible to understand modern society and its problems, ignoring philosophy. This also applies to such a social phenomenon as corruption.

It is impossible to think of more evidence that private academic controversy touches the public nerve: it has finally reached minds of large masses that the problem of corruption in society is a problem that affects everyone. With regard to the attitude to this social phenomenon, all socially active individuals have developed their opinion - not only specialists in the field of certain sciences, but also, as they say, representatives of the broadest strata of the democratic community. And this means that there is precisely a sociophilosophical problem, the formulation of which requires the removal (and sometimes even breaking) of interdisciplinary partitions and gaining access to the operational space of social philosophy, whose methodology eliminates solving particular problems when general problems are not solved. It is the social philosopher who will have to say the decisive words in justification of all those "social practices» that sooner or later will be unified into clear forms of legislative acts and socially significant decisions. This certainly applies to such a social phenomenon as corruption.

The main purpose of this study is to reveal the social essence, sources and causes of corruption in society. To achieve this goal, it is planned to solve the following research tasks:

- to consider the phenomenon of corruption, reflecting the ways of its functioning, reproduction, spreading;

- to investigate the origin of corruption as an objective phenomenon that inevitably arises in the course of social evolution in order to identify its nature of preconditions and relationships with political, legal and socio-economic social mechanisms.

\section{Methods}

The theoretical basis of the study were the works and publications of domestic and foreign lawyers, political scientists, sociologists and philosophers devoted to the study of the corruption problem: M. Weber [2], Holmes L., [3], Heidenheimer A.J. [4], N. Ambraseys, R. Bilham [5], Treisman, D. [6], Hirschi, T. [7], Cloward R., Ohlin, L. [8] Luneeva V.V. [9] and others. The main methodological approach in the philosophical analysis of corruption as an element of the social reality is the theory of social construction of reality by Peter Berger and Thomas Luckman. An additional methodological approach is the demythologization of social reality with the isolation of objective and subjective grounds for the existence of corruption and its role in the functioning of society. The disclosure of the role of cultural factors in the processes of reproduction of corrupt practices led to the use of the socio-cultural approach disclosed in the works of B. Hofstede, S.M. Lipset and G.S. Lenz. 


\section{Results}

Corruption processes take place in the overwhelming majority of states in the modern world. At the same time, the roots and causes of corruption differ depending on the historical era and the phase of the country's socio-economic development. Moreover, the norms of corrupt behavior, forms of manifestations of corruption, their results and consequences for the functioning of individual societies are different. In this regard, the level of corruption spread depends on a whole complex of reasons, which can be reduced to socio-cultural factors (national mentality, adherence to a particular religion, the presence of a moral crisis arising in the course of socio-economic reforms and political transformations); the presence of high differentiation of the population (here the duality of this phenomenon can be traced: on the one hand, the higher the social inequality, the more difficult it is for the lower circles of society to participate in the distribution of goods, and, accordingly, the higher is corruption as a way of their redistribution; on the other hand, corruption always leads to a greater differentiation of the population); the existence and effectiveness of a legal system aimed at reducing the spread of corruption.

Table 1. Ranking of countries in the world according to the Corruption Perceptions Index in 2019.

\begin{tabular}{|c|c|c|c|c|c|c|c|c|c|c|c|}
\hline 苛 & 昰 & 㫕 & ๖̈ & 预 & 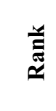 & : & 预 & 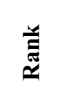 & ڤ̆ & 预 & 气 \\
\hline 87 & Denmark & 1 & 69 & France & 23 & 56 & $\begin{array}{l}\text { Czech } \\
\text { Republic } \\
\end{array}$ & 44 & 45 & Montenegro & 66 \\
\hline 87 & $\begin{array}{l}\text { New } \\
\text { Zealand }\end{array}$ & 1 & 69 & $\begin{array}{l}\text { United } \\
\text { States of } \\
\text { America }\end{array}$ & 23 & 56 & Georgia & 44 & 45 & Senegal & 66 \\
\hline 86 & Finland & 3 & 68 & Bhutan & 25 & 56 & Latvia & 44 & 44 & Hungary & 70 \\
\hline 85 & Singapore & 4 & 67 & Chile & 26 & 55 & Dominica & 48 & 44 & Romania & 70 \\
\hline 85 & Sweden & 4 & 66 & Seychelles & 27 & 55 & Saint Lucia & 48 & 44 & South Africa & 70 \\
\hline 85 & Switzerland & 4 & 65 & Taiwan & 28 & 54 & Malta & 50 & 44 & Suriname & 70 \\
\hline 84 & Norway & 7 & 64 & Bahamas & 29 & 53 & Grenada & 51 & 43 & Bulgaria & 74 \\
\hline 82 & Netherlands & 8 & 62 & Barbados & 30 & 53 & Italy & 51 & 43 & Jamaica & 74 \\
\hline 80 & Germany & 9 & 62 & Portugal & 30 & 53 & Malaysia & 51 & 43 & Tunisia & 74 \\
\hline 80 & Luxembourg & 9 & 62 & Qatar & 30 & 53 & Rwanda & 51 & 42 & Armenia & 77 \\
\hline 78 & Iceland & 11 & 62 & Spain & 30 & 53 & $\begin{array}{l}\text { Saudi } \\
\text { Arabia }\end{array}$ & 51 & 42 & Bahrain & 77 \\
\hline 77 & Australia & 12 & 61 & Botswana & 34 & 52 & Mauritius & 56 & 42 & $\begin{array}{l}\text { Solomon } \\
\text { Islands }\end{array}$ & 77 \\
\hline 77 & Canada & 12 & 60 & Israel & 35 & 52 & Oman & 56 & 41 & China & 80 \\
\hline 77 & $\begin{array}{l}\text { United } \\
\text { Kingdom } \\
\end{array}$ & 12 & 60 & Lithuania & 35 & 50 & Slovakia & 59 & 41 & Ghana & 80 \\
\hline 76 & Hong Kong & 16 & 60 & Slovenia & 35 & 48 & Cuba & 60 & 41 & India & 80 \\
\hline 75 & Belgium & 17 & 59 & $\begin{array}{l}\text { Korea, } \\
\text { South }\end{array}$ & 39 & 48 & Greece & 60 & 41 & Morocco & 80 \\
\hline 74 & Estonia & 18 & 59 & $\begin{array}{l}\text { Saint } \\
\text { Vincent and } \\
\text { the } \\
\text { Grenadines }\end{array}$ & 39 & 48 & Jordan & 60 & 40 & Burkina Faso & 85 \\
\hline 74 & Ireland & 18 & 58 & Cabo Verde & 41 & 47 & Croatia & 63 & 40 & Guyana & 85 \\
\hline 73 & Japan & 20 & 58 & Cyprus & 41 & 46 & $\begin{array}{l}\text { Sao Tome } \\
\text { and } \\
\text { Principe }\end{array}$ & 64 & 40 & Indonesia & 85 \\
\hline 71 & $\begin{array}{l}\text { United Arab } \\
\text { Emirates }\end{array}$ & 21 & 58 & Poland & 41 & 46 & Vanuatu & 64 & 40 & Kuwait & 85 \\
\hline 71 & Uruguay & 21 & 56 & Costa Rica & 44 & 45 & Argentina & 66 & 40 & Lesotho & 85 \\
\hline 39 & Turkey & 91 & 34 & Nepal & 113 & 28 & Kenya & 137 & 23 & Eritrea & 160 \\
\hline 38 & Ecuador & 93 & 34 & Philippines & 113 & 28 & Lebanon & 137 & 22 & Nicaragua & 161 \\
\hline 38 & Sri Lanka & 93 & 34 & Eswatini & 113 & 28 & Liberia & 137 & 20 & Cambodia & 162 \\
\hline 38 & Timor-Leste & 93 & 34 & Zambia & 113 & 28 & Mauritania & 137 & 20 & Chad & 162 \\
\hline
\end{tabular}




\begin{tabular}{|l|l|c|c|l|l|l|l|l|l|l|l|}
\hline 37 & Colombia & 96 & 33 & Sierra Leone & 119 & 28 & $\begin{array}{l}\text { Papua New } \\
\text { Guinea }\end{array}$ & 137 & 20 & Iraq & 162 \\
\hline 37 & Ethiopia & 96 & 32 & Moldova & 120 & 28 & Paraguay & 137 & 19 & Burundi & 165 \\
\hline 37 & Gambia & 96 & 32 & Niger & 120 & 28 & Russia & 137 & 19 & Congo & 165 \\
\hline 37 & Tanzania & 96 & 32 & Pakistan & 120 & 28 & Uganda & 137 & 19 & Turkmenistan & 165 \\
\hline 36 & Kosovo & 101 & 31 & Malawi & 123 & 26 & Guatemala & 146 & 18 & Haiti & 168 \\
\hline 36 & Panama & 101 & 30 & Azerbaijan & 126 & 26 & Honduras & 146 & 18 & Libya & 168 \\
\hline 36 & Peru & 101 & 30 & Djibouti & 126 & 26 & Iran & 146 & 17 & Korea, North & 172 \\
\hline 36 & Thailand & 101 & 30 & Kyrgyzstan & 126 & 26 & Mozambique & 146 & 16 & Afghanistan & 173 \\
\hline 35 & Albania & 106 & 30 & Ukraine & 126 & 26 & Nigeria & 146 & 16 & $\begin{array}{l}\text { Equatorial } \\
\text { Guinea }\end{array}$ & 173 \\
\hline 35 & Algeria & 106 & 29 & Guinea & 130 & 25 & Cameroon & 153 & 16 & Sudan & 173 \\
\hline 35 & Brazil & 106 & 29 & Laos & 130 & 25 & $\begin{array}{l}\text { African } \\
\text { Republic }\end{array}$ & 153 & 16 & Venezuela & 173 \\
\hline 35 & $\begin{array}{l}\text { Cote } \\
\text { d'Ivoire }\end{array}$ & 106 & 29 & Maldives & 130 & 25 & Comoros & 153 & 15 & Yemen & 177 \\
\hline 35 & Egypt & 106 & 29 & Mali & 130 & 25 & Tajikistan & 153 & 13 & Syria & 178 \\
\hline 35 & $\begin{array}{l}\text { North } \\
\text { Macedonia }\end{array}$ & 106 & 29 & Mexico & 130 & 25 & Uzbekistan & 153 & 12 & South Sudan & 179 \\
\hline 35 & Mongolia & 106 & 29 & Myanmar & 130 & 24 & Madagascar & 138 & 9 & Somalia & 180 \\
\hline 34 & El Salvador & 113 & 29 & Togo & 130 & & & & & & \\
\hline
\end{tabular}

\section{Discussion}

The deep roots and causes of corruption, depending on the historical era and phase of the country's socio-economic development, are very different. Moreover, the norms of corrupt behavior, forms of manifestations of corruption, their results and consequences, depending on the countries, are different. In this regard, it can be argued that any corruption processes are determined by specific features that largely depend on the socio-cultural environment in which they occur.

In this regard, business entities operating in certain areas in different countries, one way or another, have to consider the practices of doing business in these states, including corruption.

Let us turn to such an indicator that allows us to make cross-country comparisons, namely, the Corruption Perceptions Index, published annually by the international organization Transparency International.

According to this study, 10 points are assigned to countries with the lowest level of corruption and, accordingly, 0 points to countries with the highest corruption rates.

As this study shows (Appendix 1), although to varying degrees, corruption is characteristic of all those countries of the world that have found their place in this rating.

The use of this quantitative indicator allows us to draw a number of qualitative conclusions regarding the country-specific nature of corruption.

1. In Western countries, the level of corruption is on average much lower than in Eastern, African, South American countries.

2. Developed countries succeed in reducing the incidence of corruption better than developing countries.

3. In small countries with developed economies, the level of corruption is lower than in large countries.

4. The level of corruption in the Islamic world is traditionally high.

These facts are based, apparently, on a complex of reasons, including:

- sociocultural factors;

- high social differentiation;

- the lack of a proper anti-corruption system in developing countries;

- the desire of various organizations (including transnational corporations) to enrich themselves at the expense of such countries by bribing officials and, thus, signing of the 
contracts that are beneficial for themselves and unfavorable for the population of these states.

So, let's consider the specified complex of reasons.

Speaking about the national mentality as one of the socio-cultural factors in the development of corruption processes in separate countries, we note that there are differences between the Western and Eastern types of corruption, which are predetermined by their inherent differences in the types of social structure and spiritual life.

A number of characteristics of this dichotomy can be distinguished:

- Production is the basis for socio-economic development in the West, and the basis in the East is distribution.

- In the West, materialism, secularized realism, pragmatism, objectivism, pluralism, rationality, movement, progress, conquest of nature, law, science, freedom, individualism are distinguished as cultural characteristics. At the same time, the East is characterized by such features as subjectivism, intuitiveness, stability, inertia, naturalness, adaptation to nature, order, submission.

- Political characteristics inherent in the West - citizenship, democracy; To the East patriarchy, authoritarianism, despotism.

Such features of the East lead to the accumulation and redistribution of income received through state-controlled channels, a centralized determination of the need for the production of certain goods and services, the priority of the power vertical, and, as a result, to the existence of conditions conducive to the spread of corruption.

Also, considering the socio-cultural factors influencing the development of corruption processes, it is advisable to mention the theory of E. Hull, who introduced the concept of "context" into scientific thought.

According to his theory, in high-context cultures, the success of entrepreneurial activity is largely determined by the friendly relations of the parties, and to a much lesser extent is regulated by the regulatory and legal field. And, on the contrary, in low-context cultures, business is built on the formal side, the laws and provisions of the concluded contracts.

The first group of cultures includes the cultures of the East, including the Arab, as well as some of the peoples of the Mediterranean (Italy, Spain), within which making offerings, giving gifts are essential condition for establishing and maintaining long-term, reliable business contacts. The second includes the cultures of northern Europe, understood as broadly as possible: Great Britain, Germany, Switzerland, Scandinavia, the Netherlands.

Within the framework of considering the socio-cultural features that contribute to the spread of corruption, it seems necessary to mention the theory of G. Hofstede. He identifies a number of parameters for measuring cultures, namely: power distance, masculinity, uncertainty avoidance, as well as collectivism-individualism measurement [10].

The latter is understood by him as a measure of the collective in the individual and determines the degree of participation of group interests in making personal decisions. In cultures in which the balance of this distinction shifts towards the collective, individuals tend to violate laws, norms, rules, in those cases when they contradict the interests of his group, or traditions developed by the group to which he feels he belongs.

The distance of power is defined as the degree of agreement of individuals with the principle of uneven distribution of power. Representatives of cultures with a high degree of power distance are characterized by a strong dependence of subordinates on the leadership, when the latter provide support in exchange for loyalty to their actions. In this regard, in order to obtain certain benefits and privileges, subordinates are not able to be critical of the actions of the management, including those that are corrupt. Therefore, as a rule, the population of countries with a high-power distance is more tolerant of corruption than in countries with a low power distance. 
Using the main conclusions of this theory B. Hastid conducted a comparative analysis of corruption in 50 countries to identify the existence of links between the corruption perception index and cultural measurements. In the course of this analysis, he came to the conclusion that in states with a low level of economic, political, social development, a significant level of social inequality, as well as with a large distance of power, a shift in the balance in the structure of the collective-individual towards the collective, a higher level of corruption is clearly traced. [11, p. 432].

It is also worth noting studies that correlate religion and the level of corruption. Of course, most religions condemn corruption.

At the same time, the dogmas of religions aimed at reducing corruption are not a sufficient argument for most people not to participate in corrupt interactions.

In addition, it should be noted that using statistical methods, a number of researchers have managed to establish a link between the hierarchy of the prevailing religion in the country and the level of corruption. Countries with highly hierarchical religious systems (Catholicism, Orthodoxy, Islam) are more prone to corruption than countries with less hierarchical religions.

So, for example, is the study carried out by D. Treisman [12]. When comparing the level of corruption with the percentage of the population confessing Protestantism, in a number of countries he concluded that the degree of corruption in the state would decrease with an increase in the population size.

Thus, one of the factors in the development of corruption is belonging to a particular religion.

Perhaps, among other socio-cultural factors contributing to the spread of corruption in transitional societies, there is a moral crisis arising in the course of socio-economic reforms and political transformations. Here we should turn to the concept of social anomie. Let us recall that the state of social anomie arises in the era of reforms, when the process of destruction of old social norms is practically completed, while new norms either have not yet appeared, or have not sufficiently strengthened.

In this regard, there is a violation of the mechanism for constructing social reality, not only in the consciousness of a single individual, but also in society as a whole. In addition, the established system and the way of social life is being destructed: many practices with negative connotations cease to be negative.

In such a society a tendency towards sociocultural entropy, a decrease in the level of needs, a simplification of the rules of life behavior and a blurring of the boundaries separating what is permitted from what is prohibited are dominating. The criminal is no longer perceived as evil, it becomes not only permissible, but also possible in situations where it leads to success or benefit. An important feature of such a society is the expansion of the shadow aspects of social reality, almost universal moral and actual legalization of the criminal. In this society, the distinction between the official and the shadow practically disappears. In this regard, corruption is perceived as a completely legalized phenomenon, sometimes leading to better results at lower costs.

Thus, we can conclude that corruption is most widespread during the period of social and political reforms (revolutions, cataclysms), when a moral gap arises.

The next reason for the development of corruption processes in the modern world is a high degree of differentiation of society. In the context of the emerging significant level of social stratification, the tendency of using corrupt practices by society is increasing.

The often-emerging understanding that participation in corrupt interactions is the simplest, does not require large time and material costs, causes the individual to need such participation: he «imitates» more high-ranking or successful individuals. This effect is especially acute in situations where the former feels his intellectual superiority over the latter, while having lower earnings and status. 
Here we should also note that according to the theory of behaviorism, finding himself in a team, in a certain environment, an individual gradually learns the rules of the game that are accepted in a particular community. In this regard, if the intra-corporate (as a particular) or «intra-social» (as a whole) situation is such that corrupt actions are considered acceptable, then new employees (in organizations) or individuals (in society as a whole) will perceive such behavior as normal and will follow such guidelines in the future.

Thus, the high level of differentiation of society leads to the fact that the poor are trying to get rich as quickly as possible and for this purpose they copy the behavior of the upper strata, which often turns out to be corrupt.

Another reason for the development of corruption in individual countries is the absence or presence of a low level of a comprehensive system of measures aimed at curbing corruption processes.

The sociocultural predisposition to corruption noted above, of course, has a significant impact on the development of society, but, nevertheless, it is not the final verdict. It is possible and needed to fight with it. In this regard, it is advisable to mention examples of countries such as Singapore, Hong Kong and Botswana, which had a full range of problems typical for countries with a high level of corruption and which are currently at a fairly high place in the Corruption Perceptions Index.

\section{Conclusion}

The conducted research allows us to formulate the following conclusions:

1. Corruption is a complex social phenomenon, the characteristics of which vary in different societies. In countries with different political and social systems, corruption manifests itself in different ways, having its own specific causes and causing, therefore, different consequences. Its characteristics are significantly influenced by the features of the historical and cultural development of society, systems of domination and legitimation in power relations, the nature of the prevailing norms, traditions, values, life credos, the originality of the stage of its social and political development experienced by this or that country, etc.

2. To determine the reasons for the reproduction of corrupt practices in public relations, it is necessary to identify the objective grounds, cultural and social context of corruption and analyze the attitude of different categories of citizens to this phenomenon, from the common people to the elite. These grounds are sociocultural in nature. They are a general rule that guides the interacting parties when choosing strategies for behavior in situations of possible corruption.

3. Consequently, in order to implement an effective state policy in the field of reducing the level of corruption in society, it is necessary to understand the essence of this phenomenon. And without taking into account the socio-cultural conditions conducive to the growth of corruption in society, this is practically impossible to do. Therefore, it is important to identify the socio-cultural foundations of corruption in modern society. Then, based on the established socio-cultural foundations of corruption, a system of anticorruption measures should be built.

\section{References}

1. L. Pellegrini, Corruption, Development and the Environment (Springer, 2011)

2. M. Weber, Political works, 1895 -1919. Gesammelte Politische Schriften (Praxis, M., 2003)

3. H. Leslie, Corruption. A very short introduction (NY, 2015) 
4. A.J. Heidenheimer, Political corruption (Holt, Rinehart \& Winston, NY, 1970)

5. N. Ambraseys, R. Bilham, Corruption kills. Nature 469(7329), 153-5 (2011)

6. D. Treisman, Journal of Public Economics 76(3), 399-457 (2000)

7. T. Hirschi, Causes of Delinquency (University of California Press, Berkeley, CA, 1969)

8. R. Cloward, L. Ohlin, Delinquency and opportunity (The Free Press. New York, 1960)

9. V.V. Luneev, State and Law 4 (2000)

10. G. Hofstede, Cultures and organizations: Software of the mind (N.Y. 1997)

11. H.B. Wealth, Journal of International business Studies XXX(2), 339-346 (1999)

12. D. Treisman, The Causes of Corruption: A Cross-National Study. Unpublished manuscript (University of California, Los Angeles, 1999)

13. V.F. Lapshin, S.A. Korneev, R.V. Kilimbaev, IOP Conference Series: Materials Science and Engineering 1001, 012144 (2020) DOI: 10.1088/1757899X/1001/1/012144 